\title{
Impact on health awareness in adult childhood cancer survivors after perceiving their digital treatment summary and follow-up recommendations.
}

\section{Helena Linge}

Lunds universitet Medicinska fakulteten

Cecilia Follin ( $\square$ cecilia.follin@med.lu.se)

Lunds universitet Medicinska fakulteten https://orcid.org/0000-0003-2133-7967

\section{Research article}

Keywords: Digital, treatment summary, ehealth, late effects, childhood cancer, E health literacy

Posted Date: May 15th, 2020

DOI: https://doi.org/10.21203/rs.3.rs-28210/v1

License: (c) (i) This work is licensed under a Creative Commons Attribution 4.0 International License. Read Full License

Version of Record: A version of this preprint was published at BMC Cancer on April 1st, 2021. See the published version at https://doi.org/10.1186/s12885-021-08051-9. 


\section{Abstract}

Background: The survival rate after childhood cancer has improved and today more than $80 \%$ of patients with a paediatric malignancy will become 5-year survivors. Two thirds of CCS will experience one or several late complications due to cancer treatment, resulting in excess morbidity and mortality. These complications require regular follow-up care to preserve health, improve quality of life and increase empowerment. In addition, the survivors need education about their diagnosis, treatment history and follow-up plans, including access to their individual cancer treatment summary. This study aims to illuminate childhood cancer survivors' health awareness after perceiving their personalized digital treatment summary and follow-up recommendations.

Methods: To assess the medical background, health related survivorship experiences, and e health literacy, 16 survivors from southern Sweden with varied childhood cancer diagnoses responded to a survey before and after perceiving their digital treatment summary. Their overall experiences were assessed using focus group interviews. The transcribed data was analyzed with conventional qualitative content analysis.

Results: The results of the survey show that the self-reported medical problems as well as the perceived survivorship experiences largely reflected what is known about childhood cancer survivors in general. Of the considered medical specialists, the primary care physician was the most frequently visited specialist (68.8\%). The E health literacy correlated with level of education, but not length of survival and was not linked to CNS radiotherapy. The survivors graded the treatment summary valuable, agreeable and comprehensive. The focus group interviews identified three themes: 1) The significance of information, 2) The impact of awareness; and 3) Empowerment.

Conclusions: In conclusion, childhood cancer survivors with a broad representation of primary diagnoses, were impacted by perceiving their digital treatment history and follow up recommendations. High $\mathrm{E}$ health literacy was not associated with treatment features but with educational level and sex. Perceiving the treatment summaries furthered the survivors understanding of their health situation and consequently aided empowerment. Digital treatment summaries delivered by knowledgeable health care professionals could aid continuous health surveillance and promote the patient-health care-shared responsibility of medical follow up after childhood cancer.

\section{Background}

The survival rate after childhood cancer has improved markedly and today more than $80 \%$ of patients with a paediatric malignancy will become 5-year survivors (1). Currently, one in every 1000 young adults in developed countries is a childhood cancer survivor (CCS) (2). However, it has become evident that many childhood cancer survivors suffer from medical, cognitive and psychosocial late complications. Two thirds of CCS will experience one or several late complications due to cancer treatment, resulting in excess morbidity and mortality compared to gender matched controls (3). These complications require proper and regular follow-up care to preserve health, improve quality of life and increase empowerment (4). In addition to the follow-up care at the hospital and a longterm relationship with qualified health-care professionals, the survivors need education about their diagnosis, treatment history and follow-up plans, including access to their individual cancer treatment summary.

Previous studies report that $75 \%$ of the survivors are unaware of potential late complications after cancer treatment during childhood (5). Information about potential risks of complications is essential in order to attend follow-up care and to engage in healthy behaviour (6). Further, survivors themselves report a lack of adherence to 
recommended screening programmes, based on evidence-based guidelines, and medical examinations as they enter adulthood, which places these survivors at a particularly high risk for a chronic condition (7). Having a holistic approach when meeting with the survivors is valuable as it has been shown that the survivors require knowledge and support in order to handle and understand their complex situation (8).

The success of the model of follow-up care depends on the survivors' attendance, which is associated with the survivors' preferences and understanding of their situation $(9,10)$. Having access to and understanding the cancer treatment summary should be included in the follow-up care. There has long been a shortage of information about survivors' experiences of follow-up methods, their knowledge of late complications and their information needs $(11,12)$.

Health-care providers need more knowledge about how the survivors experience of having access to their individual cancer treatment summary and follow-up recommendations, in order to be able to increase awareness among the survivors and optimize and adapt the information to the survivors' unique needs. Therefore, this study aims to illuminate childhood cancer survivors' experiences of having access to a digital treatment summary and follow-up recommendations.

\section{Method}

\section{Digital treatment summary and follow-up recommendations}

The launch of a digital treatment summary has been described (14). In brief, registry data (15) containing treatment history pertinent to medical follow-up is presented in the format of a report.

\section{Recruitment And Participants}

Childhood cancer survivors who had participated in follow-up at the Late Effects Clinic with the last visit no longer than 6 months ago, and who were living in the southern region of Sweden were eligible for the study. Twenty-eight survivors with a varied distribution of childhood cancer diagnosis were randomly identified in the hospitals data system of patients attending the clinic during the last 6 months. They were sent a letter with information about the study which included an informed consent form to be signed and returned if they were willing to participate. Two weeks after sending the letter, one of the authors (C.F.) phoned the patients to provide further information about the study and to ask if the CCS were willing to participate. Nine survivors declined participation due to a lack of time or lack of interest, and three failed to come to the meetings. A total of 16 survivors participated in the present study.

\section{Study Design And Data Collection}

During the individual interview, each participant completed the first part of the survey. The survey was adapted from McClellan et al (16) and supplemented with 6 queries regarding e-health literacy (17). Each item in the eHEALS uses a 5-point scale to answer each question with response options ranging from "strongly agree" to "strongly disagree". After viewing and commenting on their personalized digital treatment summary on a computer screen, the second part of the survey was completed. 
Three to four months after the individual interview, participants were gathered to address survivorship issues and their experience of accessing the digital treatment summary in focus groups. A semi-structured interview guide was used to facilitate focus on the aim of the study (18). The moderator's primary focus was on helping the respondents keep to the topic. The interview started with an open question asked by the moderator (HL): "How would you describe your experience of reading and understanding your digital treatment summary?". The observer (CF) assisted by asking probing questions and taking notes and by having follow-up discussions that needed clarification during the interviews. The observer concluded the interview by giving a short summary thereof. The focus group interviews were conducted in a separate room at the university hospital library and lasted between 60 and 90 minutes. The authors considered a broad representation of sex, age and diagnosis among the survivors when assembling the groups. The survivors also had the choice to request a specific interview occasion which suited their schedule to attend.

\section{Data analysis}

The results of the survey were summarized using descriptive statistics. Multiple linear regression was used to determine the correlation between the eHealth literacy score and the variables "time since diagnosis" and "radiotherapy to CNS". We used a truncated eHEALS item set of 6 items. The reason for truncation was the seeming redundancy of the items "I know where to find helpful health resources on the Internet" and "I have the skills I need to evaluate the health resources I find on the Internet" after translation into Swedish.

The qualitative assessment was conducted as described before (8). In short, the interviews were recorded as a data file and transcribed verbatim. A conventional qualitative content analysis was used to analyze the data (19). The two authors who conducted the interviews analyzed them all. The analysis was carried out in several steps. The first step included reading the text as a whole, to gain a general understanding. In the second step, the text was read again, word for word, with a focus on identifying codes that captured key concept and thoughts. As the analysis proceeded, labels for codes emerged that were reflective of more than one key thought, and together the codes resulted in the initial coding scheme. Codes were then sorted into categories and subcategories. The authors then discussed the categories together. Themes were agreed upon and categories named and sorted under the corresponding theme.

\section{Results}

The characteristics of the study group $(n=16)$ which aimed at a broad representation of all diagnoses, are shown in Table 1. The survivors' median age at interview was 39 years and they were interviewed in median 31.5 years after cancer diagnosis. 9 survivors were treated with radiotherapy in combination with chemotherapy and 7 survivors with chemotherapy alone.

\section{Table 1. The characteristics of the survivors $(n=16)$}




\begin{tabular}{|c|c|c|c|c|c|c|c|}
\hline $\begin{array}{l}\text { Sex (male/ } \\
\text { female) }\end{array}$ & $\begin{array}{l}\text { Current age } \\
\text { (years) } \\
\text { Median } \\
\text { (range) }\end{array}$ & $\begin{array}{l}\text { Highest } \\
\text { completed } \\
\text { level of } \\
\text { education }\end{array}$ & $\begin{array}{l}\text { Current } \\
\text { level of } \\
\text { employment }\end{array}$ & 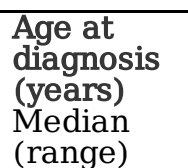 & $\begin{array}{l}\text { Time since } \\
\text { diagnosis (years) } \\
\text { Median (range) }\end{array}$ & $\begin{array}{l}\text { Any } \\
\text { RT }^{\mathrm{a}} \\
\left(\mathrm{y}^{\mathrm{b}}\right. \\
\end{array}$ & $\begin{array}{l}\mathrm{RT}^{\mathrm{a}} \text { to } \mathrm{CNS} \\
\left(\mathrm{y}^{\mathrm{b}} / \text { total }\right)^{\mathrm{c}}\end{array}$ \\
\hline $6 / 10$ & $39(23-56)$ & $\begin{array}{l}\text { Elementary } \\
\text { school } \\
1 / 16 \\
\text { Secondary } \\
\text { school } \\
10 / 16 \\
\text { University } \\
5 / 16\end{array}$ & $\begin{array}{c}\text { Employed } \\
11 / 16 \\
\text { Short term } \\
\text { disability } \\
\text { compensation } \\
1 / 16 \\
\text { Long term } \\
\text { disability } \\
\text { compensation } \\
3 / 16 \\
\text { Unemployed } \\
1 / 16\end{array}$ & $\begin{array}{c}7.19 \\
+/-4.7 \\
(2-17)\end{array}$ & $31.5(20-50)$ & $9 / 16$ & $8 / 16$ \\
\hline
\end{tabular}

${ }^{a}$ radiotherapy; ${ }^{b}$ yes ; ${ }^{c}$ total number

Survey results

Regarding their respective health status the majority of participants $(15 / 16 ; 94 \%)$ graded their health/well-being as "fair" or greater (Fig. 1). 12 of the 16 participants $(75 \%)$ had at some point in their lives been in contact with health care providers for reasons that they believed were linked to their childhood cancer treatment. In the 24 months prior to the study, the group had on average had $2.56+/-1.59$ (median 2) health care visits. The type of medical specialists which the participants had visited in the last 24 months are shown in Table 2, left panel/panel $\mathrm{A}$. The most visited specialist was the primary care provider (PCP) $(68,8 \%)$ and the least visited was psychiatrist and gastrointestinal specialists (both 0 visits). Most participants reported that they felt that their needs had been taken seriously by the health care provider (less than fair (2), fair (1), good (7), excellent (4), no replies (2)). The detailed self-reported medical issues and perceived experiences are shown in Table 2, center and right panels/panels $B$ and C. 
Table 2

Self-reported medical problems and perceived survivorship experiences

\begin{tabular}{|c|c|c|c|c|c|c|c|c|}
\hline $\begin{array}{l}\text { A. Visit to a } \\
\text { clinical } \\
\text { specialist in the } \\
\text { last } 24 \text { months } \\
\text { (item 4) }\end{array}$ & $n^{e}$ & $\%$ & $\begin{array}{l}\text { B. Self-reported } \\
\text { problems (item } \\
5 \text { ) }\end{array}$ & $\mathrm{n}$ & $\%$ & $\begin{array}{l}\text { C. Perceived } \\
\text { experiences } \\
\text { (item 7) }\end{array}$ & $\mathrm{n}$ & $\%$ \\
\hline PCP d & $11 / 16$ & 68.8 & Memory & $5 / 16$ & 31.3 & $\begin{array}{l}\text { Fear of cancer } \\
\text { reccurence }\end{array}$ & $8 / 16$ & 50 \\
\hline Counselor & $4 / 16$ & 25.0 & Learning & $5 / 16$ & 31.3 & $\begin{array}{l}\text { Feeling } \\
\text { vulnerable }\end{array}$ & $3 / 16$ & 18.8 \\
\hline Chiropractor & $2 / 16$ & 12.5 & Attention & $4 / 16$ & 25.0 & $\begin{array}{l}\text { Diminished } \\
\text { physical } \\
\text { strength }\end{array}$ & $4 / 16$ & 25.0 \\
\hline Physiotherapist & $2 / 16$ & 12.5 & $\begin{array}{l}\text { Growth } \\
\text { hormone } \\
\text { deficiency }\end{array}$ & $7 / 16$ & 43.8 & $\begin{array}{l}\text { Lacking } \\
\text { enthusiasm }\end{array}$ & $3 / 16$ & 18.8 \\
\hline Psychologist & $1 / 16$ & 6.3 & Weight & $4 / 16$ & 25.0 & $\begin{array}{l}\text { Overwhelming } \\
\text { enthusiasm }\end{array}$ & $0 / 16$ & 0 \\
\hline Cardiologist & $4 / 16$ & 25.0 & Fertility & $6 / 16$ & 37.5 & $\begin{array}{l}\text { School } \\
\text { troubles }\end{array}$ & $4 / 16$ & 25.0 \\
\hline Otolaryngologist & $3 / 16$ & 18.8 & $\begin{array}{l}\text { Physical } \\
\text { activity }\end{array}$ & $6 / 16$ & 37.5 & Fear of death & $4 / 16$ & 25.0 \\
\hline Endocrinologist & $6 / 16$ & 37.5 & Liver function & $0 / 16$ & 0 & $\begin{array}{l}\text { Change of } \\
\text { body } \\
\text { appearance }\end{array}$ & $4 / 16$ & 25.0 \\
\hline Pulmonologist & $1 / 16$ & 6.3 & Thyroid gland & $2 / 16$ & 12.5 & $\begin{array}{l}\text { Relationships } \\
\text { changed }\end{array}$ & $4 / 16$ & 25 \\
\hline Diabetes team & $2 / 16$ & 12.5 & $\begin{array}{l}\text { Pulmonary } \\
\text { function }\end{array}$ & $2 / 16$ & 12.5 & $\begin{array}{l}\text { Attention } \\
\text { deficits }\end{array}$ & $4 / 12$ & 25 \\
\hline Nephrologist & $1 / 16$ & 6.3 & $\begin{array}{l}\text { Cardiac } \\
\text { function }\end{array}$ & $3 / 16$ & 18.8 & $\begin{array}{l}\text { "Impossible to } \\
\text { work" }\end{array}$ & $3 / 16$ & 18.8 \\
\hline Neurologist & $2 / 16$ & 12.5 & Hearing loss & $6 / 16$ & 37.5 & $\begin{array}{l}\text { Feeling of } \\
\text { gratitude }\end{array}$ & $5 / 16$ & 31.3 \\
\hline Psychiatrist & $0 / 16$ & 0 & $\begin{array}{l}\text { Gastrointestinal } \\
\text { function }\end{array}$ & $1 / 16$ & 6.3 & $\begin{array}{l}\text { No one } \\
\text { understands } \\
\text { me }\end{array}$ & $5 / 16$ & 31.3 \\
\hline
\end{tabular}

${ }^{\mathbf{d}}$ primary care provider; ${ }^{\mathbf{e}}$ number; 


\begin{tabular}{|c|c|c|c|c|c|c|c|c|}
\hline $\begin{array}{l}\text { Gastrointestinal } \\
\text { specialist }\end{array}$ & $0 / 16$ & 0 & Depression & $3 / 16$ & 18.8 & $\begin{array}{l}\text { Private } \\
\text { economic } \\
\text { burden }\end{array}$ & $4 / 16$ & 25 \\
\hline \multirow[t]{7}{*}{$\begin{array}{l}\text { Other medical } \\
\text { specialist }\end{array}$} & \multirow[t]{7}{*}{$2 / 16$} & \multirow[t]{7}{*}{12.5} & Anxiety & $3 / 16$ & 18.8 & $\begin{array}{l}\text { Difficulties } \\
\text { with the }\end{array}$ & $4 / 16$ & 25 \\
\hline & & & & & & $\begin{array}{l}\text { public } \\
\text { employment }\end{array}$ & & \\
\hline & & & & & & service & & \\
\hline & & & Fatigue & $5 / 16$ & 31.3 & $\begin{array}{l}\text { Difficulties } \\
\text { with the } \\
\text { National } \\
\text { Insurance } \\
\text { Agency }\end{array}$ & $1 / 16$ & 6.3 \\
\hline & & & $\begin{array}{l}\text { Secondary } \\
\text { malignancy }\end{array}$ & $2 / 16$ & 12.5 & & & \\
\hline & & & Other & $2 / 16$ & 12.5 & & & \\
\hline & & & None & $1 / 16$ & 6.3 & & & \\
\hline
\end{tabular}

Eight participants (50\%) reported having received a treatment summary on paper, 6 reported not received (37.5\%) and $2(12.5 \%)$ were unsure. 14 reported being aware $(n=7)$, or partially aware $(n=7)$ of their personal follow-up recommendations, whereas 2 reported that they were unaware. During the present study, 4 (25\%) had planned to contact the late effect clinic.

The overall response to the digital treatment summary, its appearance, and the value of the presented information, was positive with $100 \%$ of the participants grading it "very good" or "excellent" (Fig. 1). The participants deemed the appearance agreeable and reported that the content held a high value to them. Of the 16 participants, 6 expressed that they had suggestions for changes, whereas 10 did not. The changes that were suggested included explanations of medical terms and abbreviations primarily regarding the diagnosis, e.g. SNOMED, ICD10 and "recurrence". It was expressed that the participants wanted headings and fields to be shown even when a particular treatment module was irrelevant to their medical history. Two participants expressed that personalized calls to action were lacking. Two participants reported they would view the summary once per month, and 2 reported once every 6 months (Fig. 2). The majority (12/16) of participants stated they would review the treatment summary if and when a need would arise.

With regards to the $E$ health literacy scores $9 / 16$ participants (56\%) had a score higher than 20 (maximum 30 points) (Fig. 2) 7 participants reported agreement with the statements to the degree of very well or excellent (scores 4 or 5) on 5 or more of the 6 items. Out of the 6 items, the statement which received the highest average score of the participants was "I know how to find helpful health resources on the Internet" (4.06). The statement with the lowest score was "I know what health resources are available on the Internet" (3.06).

The E health literacy sum did not correlate with "age at diagnosis", "time since diagnosis", or "CNS radiotherapy". It was however significantly correlated with $\operatorname{sex}(p=0.022, \mathrm{Cl}:-13.6--1.3)$ and the level of education $(p=0.003, \mathrm{Cl}$ : 3.9-14.6). 


\section{Focus Group Interview Results}

In the analysis of the focus group interviews, the following themes and categories were identified. Quotes are shown as examples.

\section{Theme: The Significance Of Information}

\section{Access}

The survivors highlighted the value of having access to a extensively detailed treatment summary stating the risk of potential complications. Having knowledge could have an impact on their future health status, as not knowing may lead them to think that they can ignore the risk of complications. Some survivors brought up that they were not sure about knowing too many details as it may result in negative thoughts about the future.

If it doesn't mention particular risks, you are inclined to think you are out of the woods. Evidently there are multiple things to be aware of."

" Personally, I want it to state everything. Otherwise it may lead you to think you are not at a particular kind of risk, simply because the information is lacking. "

\section{Trustworthiness}

The survivors highlighted the feeling of relief when they read the treatment history and how this information could become available to them digitally. They expressed that they with access to a treatment summary no longer had to remember the details, nor repeat their history in contact with health care. This resulted in a feeling of safety.

It is always available; I don't have to search for it.

To not have to search for the information, to not have to go on a wild goose chase to find a doctor when I have questions- which makes things easier for health care as well- to not have to hunt down the information

Further, they experienced trust when having access to data provided from professionals experienced in paediatric oncology and they stressed the importance of reliability of the information in order to feel secure.

"It is better to have a proper informative format, with proper sources and correct information. Much better than going to Google, or finding Wikipedia where sources are missing. A trustworthy source is important."

The survivors experience of unclear or incorrect information, presented to them in the past, resulting a feeling of unsafety. Being offered guided information, compared to unguided, led them to understand their cancer history and how this could influence their future life situation.

"It is always easier when there is someone to talk to. I think it is better to receive it together with someone else, like this interview, instead of receiving it in the mail."

It can be interpreted in so many different ways, if you receive it on your own. I feel much more secure knowing that I can call the late effects clinic. 
Although there was a desire for personalization of the information and a belief that this could make the treatment history more useful, the survivors also recognized the complexity of having too many details presented. Further, they stressed a feeling of doubt about the individual data collection, including at what level of detail it should be presented and the resources this would require.

" I'd like it more personalized. But that may require many different pieces of information to be retrieved and put together. I don't know if it is even possible."

\section{The Timing Of Information}

The survivors highlighted different aspects of when the information about potential risks should be provided, such as receiving honest and detailed information at the end of treatment when they were still very young. Further, they also expressed that the information could also be spaced in time to fit their particular stage of life. The survivors experienced a timeliness link between receiving the information and coping with the risks or awareness of complications.

"It makes the most sense to know all the risks from the beginning. "

But some side effects may not be evident until after 20 years- if so, you may not want to worry those people.

"It came as a shock. It worried me, and I thought -Is this really a complication of the irradiation and medication? No one had told me I could go deaf."

\section{Theme: The Impact Of Awareness}

The survivors experienced advantages, as well as disadvantages of knowing and not knowing about complications and risks of complications. They were left with a feeling of confusion and imbalance when the realized that they had poor knowledge and were unprepared for late complications. Absence of information resulted in worry among the survivors and, in the void of information, they had handled their situation on their own.

"I didn't tell my children that I had been ill. Because I was afraid that they would think that they would get sick. I've kept it a secret this entire time.

"It is really tough. The cancer diagnosis is so stigmatizing. When you tell someone you've had cancer, they look at you as if you've had one foot in the grave. "

Receiving information about complications, as well as future risks of developing complications, was an experience resulting in new insights and an increased level of confidence.

I keep the information at the back of my mind but try not to think about it on an everyday basis. Knowing is a good thing. It creates attentiveness. But it can also be hard knowing. It is a balance.

\section{Theme: Empowerment}


Receiving and understanding treatment information and follow-up recommendations led the survivors towards an increased health-related self-confidence. They expressed that preventive measures in terms of lifestyle choices were closer at hand after they had become aware of their risks.

"Knowledge is power- the more you know the more you can be attentive of signs or symptoms"

"I can adjust my habits in order to reduce the risks, if I am in a high risk group."

The survivors desire of more information, including their interest in understanding the nuances of the treatments and medical follow-up, showed their willingness to take more responsibility of and to play an active role in their own health situation. This can be interpreted as an expression of empowerment among the survivors.

I would have liked to have much more information- all areas, medical charts, and what to keep in mind afterwards. If it doesn't mention particular risks, you are inclined to think you are out of the woods. Evidently there are multiple things to be aware of.

" Personally, I want it to state everything. Otherwise it may lead you to think you are not at a particular kind of risk, simply because the information is lacking. "

\section{Discussion}

The present study shows childhood cancer survivors positive experience of having access to their digital cancer treatment summary. In general, they were satisfied with the content of the received information which held a high value to them. In addition, we also show the impact of information and awareness about treatment summary and follow-up recommendations resulting in safety and empowerment among survivors. Participants with a broad scope of childhood cancer diagnoses including a relatively long follow-up time were included. Using mixed methodology, we sought to determine the current health status of 16 CCS and how they perceived receiving digital access to their treatment summary and risk group-based follow-up information. There are challenges with providing the survivors with information about possible complications which may result in a feeling of vulnerability. However, the digital treatment summary and follow-up recommendations provide a platform to educate and support the CCS during adult life to engage in self-care. Indeed, in the present study we report the survivors desire of information, including their willingness to play an active role in their own health-situation. This is in line with McClellan et al. (2013) reporting a need of access to information among CCS, in particular in survivors who have received intense treatment.

When evaluating different models on how to present a care plan it is crucial to take into account the survivors' preferences and experiences. Previous studies show the survivors' experiences of having their complications poorly explained (20) and also how they experienced unanswered questions after a visit to the clinic (21). In addition, the CCS in the current study stressed the desire to receive the information through health care channels. The current study points to important aspects of how it would be perceived by CCS if they received their treatment summary in a digital format in concordance with, or separation from, the late effects clinic. Thus, providing follow-up care at the Late effect clinic in combination with access to digital summary and care plan could be a way to improve the survivor's health awareness and adherence to follow-up recommendations.

The results from the focus group interviews demonstrate the strength of having access to the information but also the need to have it delivered and interpreted to create understanding together with a trusted party ie the late effects 
clinic professionals. A Norwegian study recently investigated the preferences for follow-up care after childhood lymphoma (22). The preference in that study was in favor of professionals with necessary knowledge over PCPs, nurse practitioners, internet, self-help or peer help. Ramsay et al (2018) determined the follow up care preferences of cancer survivors diagnosed between ages 15-39 (23) and found that a continued relationship with their oncologist was preferred. In our study the PCP was the most visited health care representative. This points to a discrepancy in the delivery of care and as the late effects clinic matures over time this discrepancy may be diminished. It is interesting that although receiving a treatment summary was an inclusion criterion for enrollment in our study, only half of the participants replied affirmatively to this question. This may indicate lack of clarity in the health care situation, a stress-related memory loss which may be specific or unspecific for the CCS. It may also indicate a need for novel approaches in delivering the information.

As expected, and in concordance with previously recognized late effects, we found that the following somatic late effects were widely reported (from $25 \%$ or more of the participants): Growth hormone deficiency, Fertility issues, Physical activity issues, Hearing loss, and overweight. The impaired cognitive function such as problems with Memory, Learning, and Attention and also fatigue were reported among $25 \%$ or more of the survivors. Only $6.3 \%$ experienced no late effects. This is in agreement with that $2 / 3$ of CCS will experience late complications (3). Among the perceived experiences, fear of cancer recurrence was the most widely reported. Overall the reported health statuses reflect expected findings, including the wide distribution of diagnoses and treatment protocols of the CCS included in the study.

The eHEALS items measures an individual's knowledge of health information resources on the Internet and more specifically, the perceived confidence in their ability to locate, evaluate, and use this health information to make informed health decisions (17). To the best knowledge of the authors, E health literacy has not been assessed for childhood cancer survivors before. It has however been assessed in adult patients with lung cancer survivors ( $\mathrm{n}=$ 83; median age 71 (range 44.89)) (24). The Milne study grouped participants into high self-perceived eHealth Literacy (scored a 4 or 5 on at least 5 out of the 8 eHEALS items) and low self-perceived eHealth literacy. In our study 7/16 would be classified as high self-perceived e health literate, reporting a score of 4 or 5 on 5 out of the 6 items used in the current study. Despite the relatively small sample size and the truncated eHEALS, we found that the total eHEALS score correlated with sex and level of education but not time since diagnosis, or whether patients had received radiation therapy to the CNS. The correlation to overall educational level is consistent with the findings of others $(24,25)$. Awareness about the level of e health literacy may help guide health care providers and policy makers to what extent health-related information can be communicated via digital resources. Measuring and reporting e health literacy is hence a step towards reaching a shared responsibility for survivorship after childhood cancer.

In summary, we assessed the self-reported and self-perceived health status and e health literacy of 16 CCS and followed their experiences through focus group interviews to explore how a digital treatment summary may contribute to awareness and empowerment among the survivors. We report that a digital summary together with follow up recommendations delivered by knowledgeable professionals may improve adherence and promote CCS long term health.

\section{Conclusion}

In conclusion, childhood cancer survivors with a broad representation of primary diagnoses, were impacted by perceiving their digital treatment history and follow up recommendations. High E health literacy was not

Page $11 / 16$ 
associated with treatment features but with educational level and sex. Perceiving the treatment summaries furthered the survivors understanding of their health situation and consequently aided empowerment. Digital treatment summaries delivered by knowledgeable health care professionals could aid continuous health surveillance and promote the patient-health care-shared responsibility of medical follow up after childhood cancer.

\section{Abbreviations}

CCS: childhood cancer survivor

CNS: central nervous system

$\mathrm{RT}$ : radiotherapy

PCP: primary care provider

$\mathrm{N}$ : number

\section{Declarations}

\section{Ethics approval and consent to participate}

Ethical approval: The study was submitted and approved by the Regional Ethics Board, Lund, Sweden (reg. no. $2011 / 770$ and 2015/876). All procedures performed were in accordance with ethical standards of the national research committee and with 1964 Helsinki declaration and its later amendments or comparable ethical standards. Written informed consent was obtained from all individual participants included in the study.

\section{Consent for publication}

Not applicable

\section{Availability of data and material}

The datasets used and/or analyzed during the current study are available from the corresponding author on reasonable request.

\section{Competing interests}

HL has co-founded and is part-time employed by a start-up company (Concidera Health) that develops decision support tools. The study design and data collection in the current work was performed prior to the founding of the company.

CF has no conflict of interest.

\section{Funding}

The authors have funding from The Swedish Childhood Cancer Fund (Barncancerfonden) grants PR2018-0034 (HL) and KP 2017-0007 (CF). The funding sources had no role in the design and conduct of the study; collection, management, analysis, and interpretation of the data; preparation, review, or approval of the manuscript; and decision to submit the manuscript for publication. 


\section{Authors' contributions}

Both authors contributed to the study conception and design. Material preparation, data collection and analysis were performed by $\mathrm{HL}$ and $\mathrm{CF}$. The first draft of the manuscript was written by both authors and all authors commented on previous versions of the manuscript. Both authors read and approved the final manuscript.

\section{Acknowledgements}

We gratefully acknowledgement The Swedish Childhood Cancer Fund (Barncancerfonden)

\section{References}

1. Howlader N, Krapcho M, Neyman N. SEER Cancer Statistics Review 1975-1998.

2. Olsen JH, Moller T, Anderson H, Langmark F, Sankila R, Tryggvadottir L, et al. Lifelong cancer incidence in 47,697 patients treated for childhood cancer in the Nordic countries. J Natl Cancer Inst 2009 Jun 3;101(11):806-813.

3. Oeffinger KC, Mertens AC, Sklar CA, Kawashima T, Hudson MM, Meadows AT, et al. Chronic health conditions in adult survivors of childhood cancer. N Engl J Med. 2006 Oct;12(15):1572-82. 355(.

4. Oeffinger KC, Wallace WH. Barriers to follow-up care of survivors in the United States and the United Kingdom. Pediatr Blood Cancer 2006 Feb;46(2):135-142.

5. Kadan-Lottick NS, Robison LL, Gurney JG, Neglia JP, Yasui Y, Hayashi R, et al. Childhood cancer survivors' knowledge about their past diagnosis and treatment: Childhood Cancer Survivor Study. JAMA 2002 Apr 10;287(14):1832-1839.

6. Landier W, Bhatia S, Eshelman DA, Forte KJ, Sweeney T, Hester AL, et al. Development of risk-based guidelines for pediatric cancer survivors: the Children's Oncology Group Long-Term Follow-Up Guidelines from the Children's Oncology Group Late Effects Committee and Nursing Discipline. J Clin Oncol 2004 Dec 15;22(24):4979-4990.

7. Krull KR, Annett RD, Pan Z, Ness KK, Nathan PC, Srivastava DK, et al. Neurocognitive functioning and healthrelated behaviours in adult survivors of childhood cancer: a report from the Childhood Cancer Survivor Study. Eur J Cancer. 2011 Jun;47(9):1380-8.

8. Palsson A, Malmstrom M, Follin C. Childhood leukaemia survivors' experiences of long-term follow-ups in an endocrine clinic - A focus-group study. Eur J Oncol Nurs. 2017 Feb;26:19-26.

9. Friedman DL, Freyer DR, Levitt GA. Models of care for survivors of childhood cancer. Pediatr Blood Cancer. 2006 Feb;46(2):159-68.

10. Absolom K, Greenfield D, Ross R, Horne B, Davies H, Glaser A, et al. Predictors of clinic satisfaction among adult survivors of childhood cancer. Eur J Cancer. 2006 Jul;42(10):1421-7.

11. Gibson F, Aslett H, Levitt G, Richardson A. Follow up after childhood cancer: A typology of young people's health care need. Clinical Effectiveness in Nursing. 2005;9(3-4):133.

12. Earle E, Davies H, Greenfield D, Ross R, Eiser C. Follow-up care for childhood cancer survivors: a focus group analysis. Eur J Cancer. 2005;41(18):2882.

13. World M, Association. World Medical Association Declaration of Helsinki: Ethical Principles for Medical Research Involving Human Subjects.: World Medical Association; 2004. 
14. Petersson-Ahrholt M, Wiebe T, Hjorth L, Relander T, Linge HM. Development and Implementation of Survivorship Tools to Enable Medical Follow-Up After Childhood Cancer Treatment in Southern Sweden. JCO Clin Cancer Inform. 2019 Jun;3:1-6.

15. Wiebe T, Hjorth L, Marotta Kelly M, Linge HM, Garwicz S. A population based pediatric oncology registry in Southern Sweden: the BORISS registry. Eur J Epidemiol. 2018 Nov;33(11):1125-9.

16. McClellan W, Klemp JR, Krebill H, Ryan R, Nelson EL, Panicker J, et al. Understanding the functional late effects and informational needs of adult survivors of childhood cancer. Oncol Nurs Forum 2013 May 1;40(3):254-262.

17. Norman CD, Skinner HA. eHEALS: The eHealth Literacy Scale. J Med Internet Res 2006 Nov 14;8(4):e27.

18. Krueger RA, Casey MA. Focus groups: a Practical guide for Applied Research. Thousand Oakes: SAGE publications; 2009.

19. Hsieh HF, Shannon SE. Three approaches to qualitative content analysis. Qual Health Res. 2005 Nov;15(9):1277-88.

20. Mayes J, Brown MC, Davies N, Skinner R. Health promotion and information provision during long-term followup for childhood cancer survivors: A service evaluation. Pediatr Hematol Oncol. 2016 Sep;33(6):359-70.

21. Knijnenburg SL, Kremer LC, van den Bos C, Braam KI, Jaspers MW. Health information needs of childhood cancer survivors and their family. Pediatr Blood Cancer. 2010 Jan;54(1):123-7.

22. Lie HC, Mellblom AV, Brekke M, Finset A, Fossa SD, Kiserud CE, et al. Experiences with late effects-related care and preferences for long-term follow-up care among adult survivors of childhood lymphoma. Support Care Cancer. 2017 Aug;25(8):2445-54.

23. Ramsay JM, Mann K, Kaul S, Zamora ER, Smits-Seemann RR, Kirchhoff AC. Follow-Up Care Provider Preferences of Adolescent and Young Adult Cancer Survivors. J Adolesc Young Adult Oncol. 2018 Apr;7(2):204-9.

24. Milne RA, Puts MT, Papadakos J, Le LW, Milne VC, Hope AJ, et al. Predictors of High eHealth Literacy in Primary Lung Cancer Survivors. J Cancer Educ. 2015 Dec;30(4):685-92.

25. Halwas N, Griebel L, Huebner J. eHealth literacy, Internet and eHealth service usage: a survey among cancer patients and their relatives. J Cancer Res Clin Oncol 2017 Nov;143(11):2291-2299.

\section{Figures}




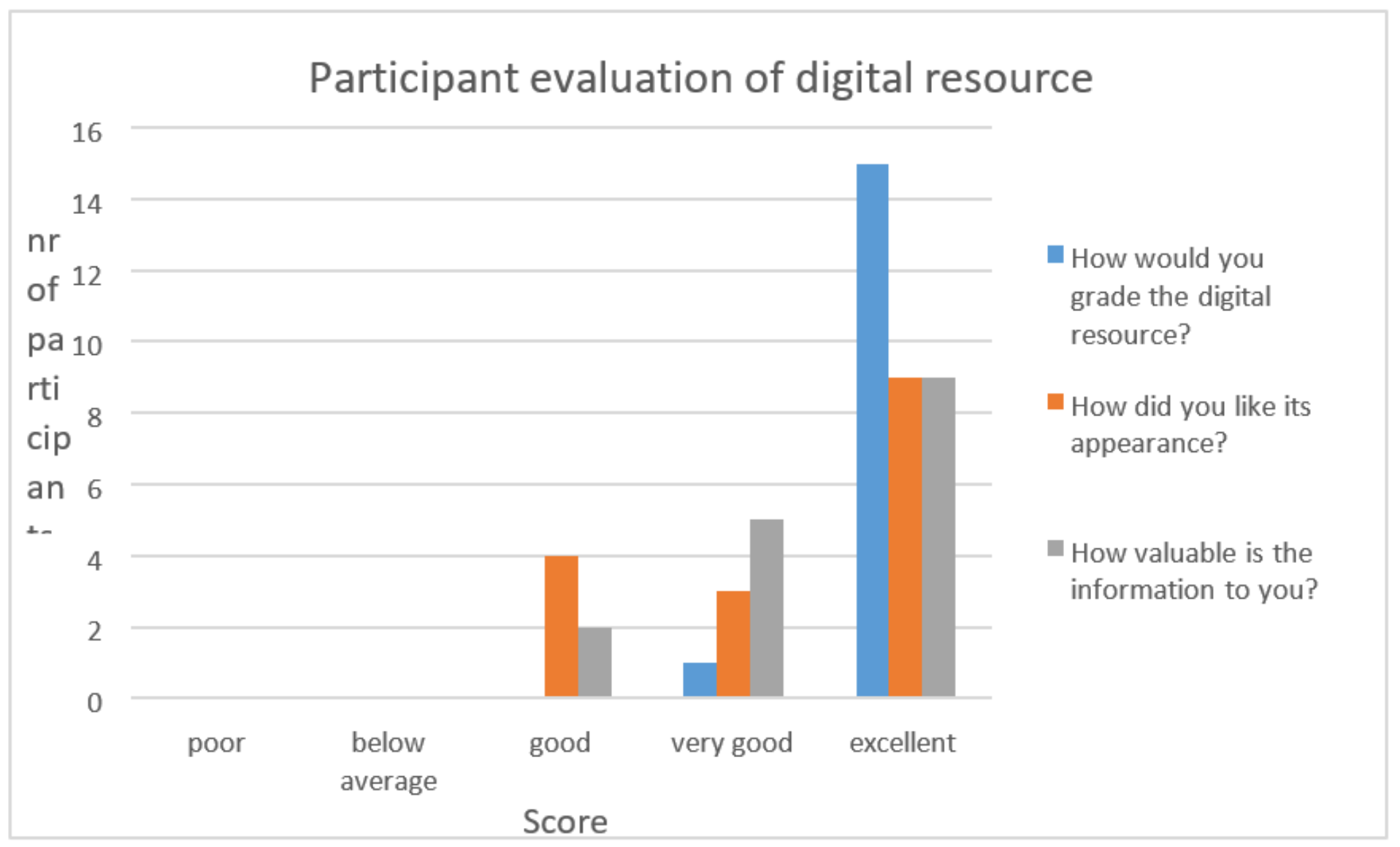

Figure 1

Participant evaluation of digital resource 


\section{Combined ehealth literacy score}

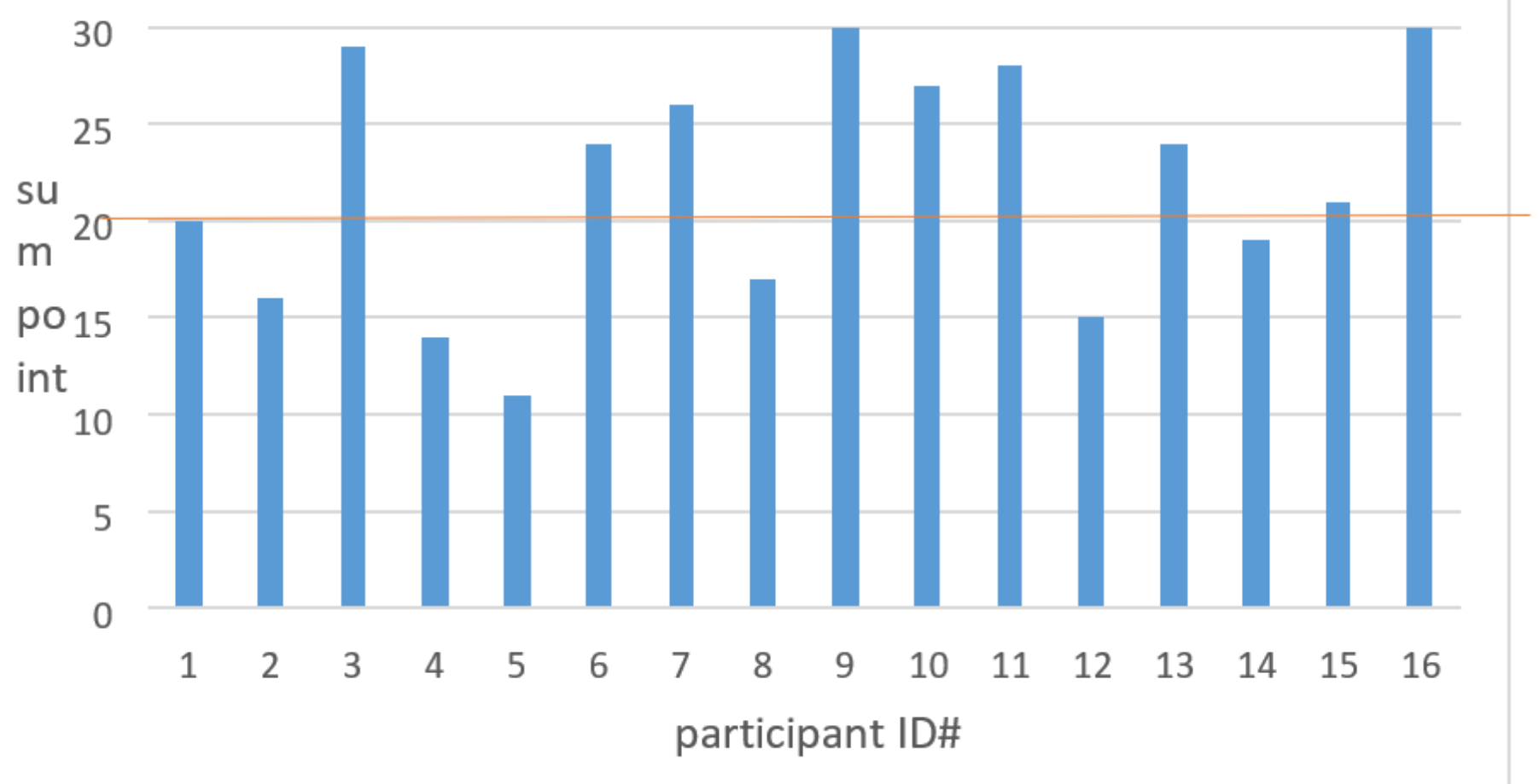

Figure 2

Total ehealth literacy score 